\title{
Grey matter abnormalities in Tourette syndrome: an activation likelihood estimation meta-analysis
}

\author{
Fang Wen, Junjuan Yan, Liping Yu, Fang Wang, Jingran Liu, Ying Li ${ }^{*+}$ and Yonghua Cui ${ }^{*}$ (D)
}

\begin{abstract}
Background: Tourette syndrome (TS) is a neurodevelopmental disorder defined by the continual presence of primary motor and vocal tics. Grey matter abnormalities have been identified in numerous studies of TS, but conflicting results have been reported. This study was an unbiased statistical meta-analysis of published neuroimaging studies of TS structures.
\end{abstract}

Methods: A voxel quantitative meta-analysis technique called activation likelihood estimation (ALE) was used. The meta-analysis included six neuroimaging studies involving 247 TS patients and 236 healthy controls. A statistical threshold of $p<0.05$ was established based on the false discovery rate and a cluster extent threshold of 50 voxels.

Results: We found that grey matter volumes were significantly increased in the bilateral thalamus, right hypothalamus, right precentral gyrus, left postcentral gyrus, left inferior parietal lobule, right lentiform nucleus, and left insula of TS patients compared to those of healthy controls. In contrast, grey matter volumes were significantly decreased in the bilateral postcentral gyrus, bilateral anterior cingulate, bilateral insula, left posterior cingulate and left postcentral gyrus of TS patients compared to those of healthy controls.

Conclusions: Our present meta-analysis primarily revealed significant increases in grey matter volumes in the thalamus and lentiform nucleus, and decreased grey matter volumes in the anterior cingulate gyrus, of TS patients compared to those in healthy controls. Most of these identified regions are associated with cortico-striato-thalamocortical circuits. Further studies with larger sample sizes are needed to confirm these changes in grey matter volumes in TS patients.

Keywords: Grey matter, Tourette syndrome, ALE, Voxel-based morphometry, Thalamus

\section{Background}

Tourette syndrome (TS) is a neurodevelopmental disorder defined by the continual presence of primary motor and vocal tics [1]. TS is mainly diagnosed by observing symptoms and by referring to disease history [2]. Magnetic resonance imaging (MRI) has enabled early diagnosis, treatment, evaluation, and pathogenic studies

\footnotetext{
* Correspondence: liying@bch.com.cn; cuiyonghua@bch.com.cn

${ }^{\dagger}$ Ying Li and Yonghua Cui contributed equally to this work.

Department of Psychiatry, Beijing Children's Hospital, Capital Medical

University, National Center for Children Healthy, 56 Nanlishi Road, Beijing, China
}

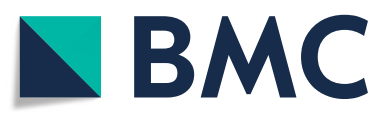

(C) The Author(s). 2021 Open Access This article is licensed under a Creative Commons Attribution 4.0 International License, which permits use, sharing, adaptation, distribution and reproduction in any medium or format, as long as you give appropriate credit to the original author(s) and the source, provide a link to the Creative Commons licence, and indicate if changes were made. The images or other third party material in this article are included in the article's Creative Commons licence, unless indicated otherwise in a credit line to the material. If material is not included in the article's Creative Commons licence and your intended use is not permitted by statutory regulation or exceeds the permitted use, you will need to obtain permission directly from the copyright holder. To view a copy of this licence, visit http://creativecommons.org/licenses/by/4.0/ The Creative Commons Public Domain Dedication waiver (http://creativecommons.org/publicdomain/zero/1.0/) applies to the data made available in this article, unless otherwise stated in a credit line to the data. of TS. It has been suggested that TS arises from neurobiological abnormalities, of which imaging studies have revealed many relevant clues $[3,4]$. For example, basal ganglia grey matter volume decreased and dorsolateral prefrontal area increased in children with TS [5]. Smaller corpus-callosum volumes and thinner sensorimotor cortices have been also reported in structural imaging studies on TS [6, 7]. It indicated that some of these regions with grey matter abnormalities may be associated with cortico-striato-thalamo-cortical (CSTC) circuits in TS $[5,8,9]$. However, identification of the specific regions 
of grey matter abnormalities linked to the CSTC circuit of TS requires further investigation.

Moreover, previous imaging studies on grey matter abnormalities in TS patients have yielded conflicting results. For instance, in previous imaging studies in TS patients, grey matter volumes are decreased in the basal ganglia and left hippocampal gyrus, as well as in orbitofrontal, anterior cingulate, and bilateral ventrolateral prefrontal cortices [10], whereas such volumes are increased in dorsal-lateral prefrontal regions $[10,11]$, the bilateral ventral putamen [12], posterior thalamus, and hypothalamus. However, decreased grey matter volumes have also been reported in the putamen and some prefrontal regions [13]. Hence, these conflicting findings indicate that grey matter abnormalities in TS patients remain unclear and that further studies are needed.

Therefore, in the present study, we performed a metaanalysis on the results of studies reporting grey matter abnormalities in TS patients. Activation likelihood estimation (ALE), a quantitative meta-analysis for imaging studies, is a statistically-based approach that we used to analyze results of grey matter volumes across studies. Due to most published studies on TS using voxel-based morphometry (VBM) to assess grey matter volumes, we performed VBM-based ALE analysis to assess previous results of grey matter volumes in TS patients.

\section{Methods}

\section{Study selection}

PubMed, Web of Knowledge, Elsevier, and PsycINFO were searched for articles published between January 31, 2006, and December 31, 2019. The following keywords were used: Tourette syndrome, MRI; Tic disorder, MRI; TS, MRI; Tourette syndrome, grey matter; Tic disorder, grey matter; TS, grey matter. The inclusion criteria for articles were as follows: (1) TS diagnosis based on either the Diagnostic and Statistical Manual of Mental Disorders, 4th Edition, text revision (DSM-IV-TR) or DSM-5 criteria for TS; (2) Grey matter changes were reported by volumes, thicknesses, or densities in structural MRIs; (3) The foci were reported in either Talairach space or the Montreal Neurological Institute (MNI) space; (4)

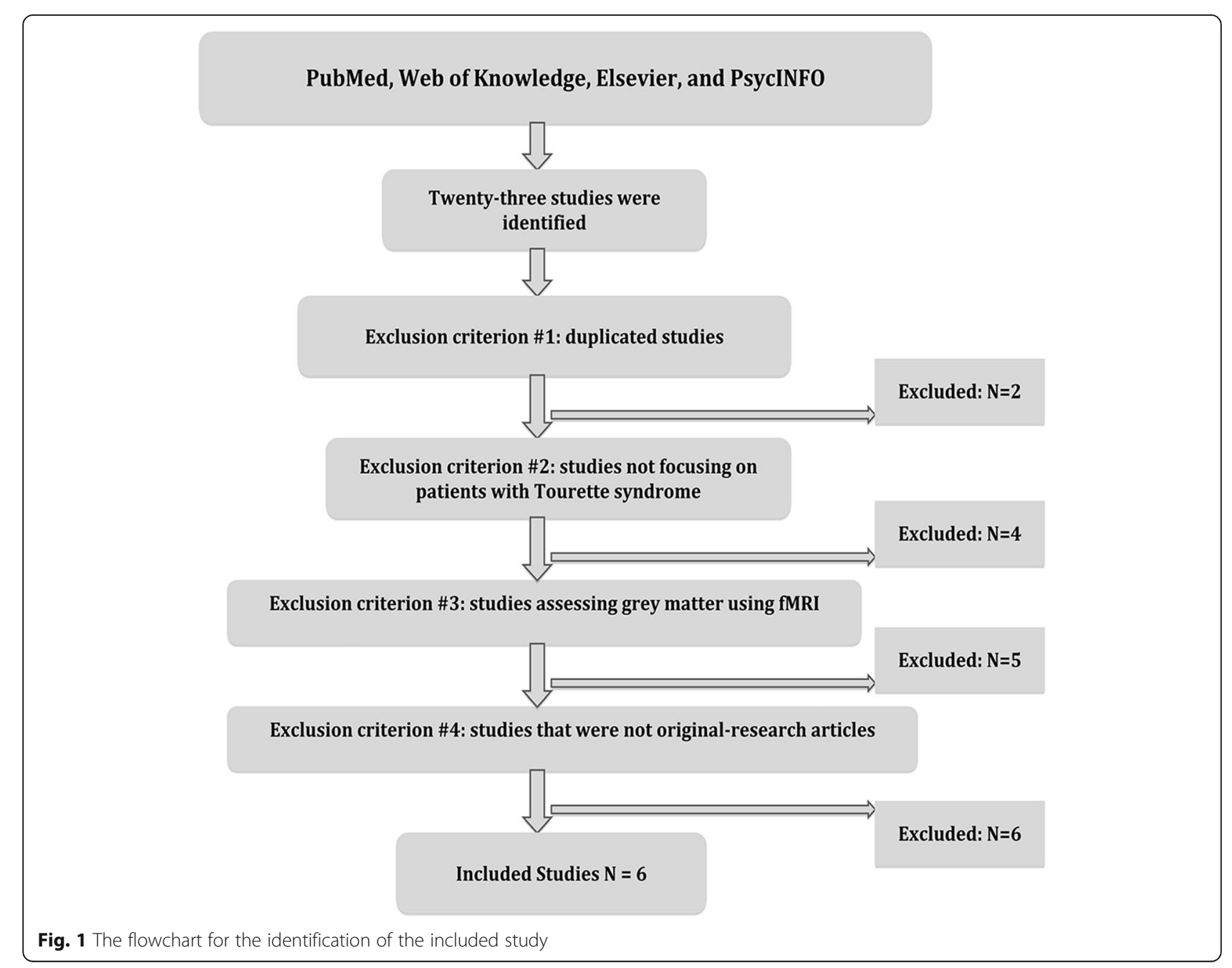


The search was confined to English- language articles. The exclusion criteria for articles were as follows: (1) duplicated studies; (2) articles that were not original studies; or (3) no coordinates of grey matter were reported.

Ultimately, a total of six studies (247 TS patients and 236 healthy controls) were included in the present meta- analysis. Figure 1 shows a flowchart depicting our steps in the identification of relevant studies. Information on ages, percentages of males, coordinates, measures, Yale Global Tic Severity Scale (YGTSS) values, and the main findings of each study were extracted (Table 1). Additionally, a total of 6 fMRI studies of tic disorders were

Table 1 Demographic characteristics of subjects and Summary of articles included in ALE meta-analysis of TS

\begin{tabular}{|c|c|c|c|c|c|c|c|c|c|c|}
\hline $\begin{array}{l}\text { First } \\
\text { Author }\end{array}$ & Year & $\begin{array}{l}\text { YGTSS } \\
(\bar{x} \pm s)\end{array}$ & $\mathbf{N}$ & $\begin{array}{l}\text { Age( } \\
\bar{x} \pm s)\end{array}$ & $\begin{array}{l}\text { Males } \\
(\%)\end{array}$ & DOI & $\begin{array}{l}\text { TS, } \\
\mathrm{HC}\end{array}$ & Coordinates & Measure & Main Findings \\
\hline Greene & 2017 & $\begin{array}{l}18.1 \pm \\
8.3\end{array}$ & 103 & $\begin{array}{l}11.9 \pm \\
2.1\end{array}$ & 78.64 & $\mathrm{~N} / \mathrm{A}$ & $\begin{array}{l}103 \\
103\end{array}$ & $\mathrm{MNI}$ & GMV & $\begin{array}{l}\text { The TS group demonstrated lower WM volumes bilaterally } \\
\text { in orbital and medial prefrontal cortices, and greater GM } \\
\text { volumes in the posterior thalamus, hypothalamus, and } \\
\text { midbrain. In a multiple regression analysis for the relative } \\
\text { volume in each significant cluster, we modeled YGTSS and } \\
\text { age as factors and their interaction. The YGTSS effect and } \\
\text { the YGTSS } \times \text { age interaction was not significant in any of } \\
\text { the models, suggesting our results reflected diagnosis } \\
\text { rather than cross-sectional tic severity. }\end{array}$ \\
\hline Muellner & 2015 & $\begin{array}{l}17.64 \pm \\
7.05\end{array}$ & 52 & $\begin{array}{l}29.5 \pm \\
8.51\end{array}$ & 55.77 & $\mathrm{~N} / \mathrm{A}$ & $\begin{array}{l}52 \\
52\end{array}$ & $\mathrm{MNI}$ & $\mathrm{N} / \mathrm{A}$ & $\begin{array}{l}\text { Lower depth and reduced thickness of gray matter was } \\
\text { found in the pre- and post-central gyri, as well as superior, } \\
\text { inferior, and internal frontal sulci. A negative correlation of } \\
\text { YGTSS/50 score with sulcal depth of the superior temporal } \\
\text { sulcus and central sulcus on the right. }\end{array}$ \\
\hline Draper & 2015 & $\mathrm{~N} / \mathrm{A}$ & 35 & $\begin{array}{l}14 \pm \\
3.1\end{array}$ & 91.43 & $\mathrm{~N} / \mathrm{A}$ & $\begin{array}{l}35 \\
29\end{array}$ & $\mathrm{MNI}$ & GMT & $\begin{array}{l}\text { PSP was inversely associated with grey matter thickness } \\
\text { within insular and sensorimotor cortices. Grey matter } \\
\text { thickness was significantly reduced in these areas in } \\
\text { individuals with TS. PSP ratings were significantly } \\
\text { correlated with tic severity. Premonitory Urge for Tics Scale } \\
\text { scores that were negatively correlated with grey matter } \\
\text { thickness were identified in clusters located within } \\
\text { sensorimotor cortical areas and within the left insular } \\
\text { cortex. By contrast, there were no significant clusters of } \\
\text { positive correlations between PUTS scores and cortical } \\
\text { grey matter thickness. }\end{array}$ \\
\hline Liu & 2013 & $\begin{array}{l}41.71 \pm \\
12.46\end{array}$ & 21 & $\begin{array}{l}7.9 \pm \\
1.95\end{array}$ & 95.24 & $\begin{array}{l}1.84 \pm \\
0.56\end{array}$ & $\begin{array}{l}21 \\
20\end{array}$ & $\mathrm{MNI}$ & GMV & $\begin{array}{l}\text { Brain volume changes were found in the left superior } \\
\text { temporal gyrus, bilateral paracentral gyrus, right } \\
\text { precuneous cortex, right pre- and post-central gyrus, left } \\
\text { temporal-occipital fusiform cortex, right frontal pole, and } \\
\text { left lingual gyrus in TS patients. Increases were found in } \\
\text { the anterior thalamic radiation, right cingulum bundle pro- } \\
\text { jecting to the cingulate gurus, and the forceps minor. De- } \\
\text { creases in white matter volume (WMV) were found in the } \\
\text { right frontal pole. No correlations between gray matter } \\
\text { volume change and YGTSS scores or tic duration were } \\
\text { found. }\end{array}$ \\
\hline Draganski & 2010 & $\begin{array}{l}28.7 \pm \\
7.4\end{array}$ & 40 & $\begin{array}{l}32.4 \pm \\
11\end{array}$ & 75 & $\begin{array}{l}24 \pm \\
11.6\end{array}$ & $\begin{array}{l}40 \\
40\end{array}$ & $\mathrm{MNI}$ & $\begin{array}{l}\text { GMV\& } \\
\text { GMT }\end{array}$ & $\begin{array}{l}\text { Reductions in grey matter volume were found in } \\
\text { orbitofrontal, anterior cingulate, and ventrolateral } \\
\text { prefrontal cortices bilaterally. Cortical thinning extended } \\
\text { into the limbic mesial temporal lobe. The VBM analysis } \\
\text { failed to demonstrate any significant correlation between } \\
\text { grey matter volume and overall tic severity (YGTSS). }\end{array}$ \\
\hline $\begin{array}{l}\text { Müller- } \\
\text { Vahl }\end{array}$ & 2009 & 28.8 & 19 & 30.4 & 100 & N/A & $\begin{array}{l}19, \\
20\end{array}$ & $\mathrm{MNI}$ & GMV & $\begin{array}{l}\text { Decreases in gray matter volumes were found in } \\
\text { prefrontal areas, the anterior cingulate gyrus, sensorimotor } \\
\text { areas, left caudate nucleus, and left postcentral gyrus. } \\
\text { Decreases in white matter volumes were detected in the } \\
\text { right inferior frontal gyrus, left superior frontal gyrus, and } \\
\text { the anterior corpus callosum. Increases were found in the } \\
\text { left middle frontal gyrus and left sensorimotor areas. In } \\
\text { MTI, white matter reductions were seen in the right } \\
\text { medial frontal gyrus and inferior frontal gyrus bilaterally, as } \\
\text { well as in the right cingulate gyrus. The YGTSS score was } \\
\text { negatively correlated with GMV. }\end{array}$ \\
\hline
\end{tabular}


identified. The main findings of each fMRI were present in sTable 1(Supplementary Material).

\section{Activation likelihood estimation (ALE)}

Neuroimaging studies usually report the peak coordinates (FOCI) of the activated brain regions under several contrast conditions. Finding the consistency of activation positions in multiple studies is more in line with the characteristics of current neuroimaging research. Therefore, ale analysis based on the coordinate data reported in the literature has gradually become the mainstream of data element analysis of neuroimaging [14].

ALE is to estimate the probability of co-activation of various brain regions in a certain task state. ALE method firstly calculates the activation possibility of each voxel in the whole brain under certain conditions in each experiment and then tests the stability of voxel activation across experiments [15]. ALE method assumes that the possibility that the whole brain voxels are included in the brain area represented by a certain activation peak point is assumed as follows: this possibility is centred on the activation peak point and presents a 3D Gaussian distribution [16]. In this distribution, voxels close to the activation peak are more likely to be activated than those far from the activation peak. Based on this idea, the ALE method can calculate the activation possibility of each voxel in the whole brain. All meta-analysis was accomplished by applying the ALE technique [17], which has been implemented in the Brain Map [18]. ALE analyses were carried out in Talairach space, and a Lancaster transform was conducted if coordinates were instead originally reported in Montreal Neurological Institute (MNI) space [19]. Brett's formula [20] and the Lancaster method were used in the transition from MNI space to Talairach space. ALE analysis of TS included six studies comprised of 208 foci. The resulting statistical maps were corrected for multiple comparisons using false discovery rates (FDRs) and were then thresholded at $p<0.05$, with a clusterextent threshold of 50 voxels.

\section{Results}

ALE results showed that grey matter volumes were significantly increased in the left thalamus, left red nucleus, right thalamus, right hypothalamus, right precentral gyrus, left postcentral gyrus, left inferior parietal lobule, right putamen, and left insula of TS patients compared

Table 2 Results of ALE analyses on grey matter abnormalities in TS patients

\begin{tabular}{|c|c|c|c|c|c|}
\hline Cluster\# & Volume $\left(\mathrm{mm}^{3}\right)$ & Peak ALE value & $Z$ values & Talairach coordinates $(x, y, z)$ & Brain regions \\
\hline \multicolumn{6}{|c|}{ Groups with increased grey matter volumes } \\
\hline \multirow[t]{2}{*}{1} & \multirow[t]{2}{*}{952} & \multirow{2}{*}{$\begin{array}{l}0.019318 \\
0.016552817\end{array}$} & 5.344082 & \multirow{2}{*}{$\begin{array}{l}-12,-30,10 \\
-14,-28,-2\end{array}$} & \multirow[t]{2}{*}{ (L) Thalamus (61.3\% Pulvinar, 2.5\% Medial Geniculate Body) } \\
\hline & & & 4.7613444 & & \\
\hline \multirow[t]{2}{*}{2} & \multirow[t]{2}{*}{784} & \multirow{2}{*}{$\begin{array}{l}0.01593744 \\
0.015419524\end{array}$} & 4.662963 & \multirow{2}{*}{$\begin{array}{l}-2,-6,-6 \\
0,-16,-8\end{array}$} & \multirow[t]{2}{*}{ (L) Thalamus (Red Nucleus) } \\
\hline & & & 4.5910673 & & \\
\hline 3 & 480 & 0.019446805 & 5.3822155 & $12,-30,13$ & (R) Thalamus (100\% Pulvinar) \\
\hline 4 & 424 & 0.016458694 & 4.751242 & $16,-28,-2$ & (R) Thalamus (16.7\% Pulvinar) \\
\hline 5 & 384 & 0.015193136 & 4.555133 & $20,-22,68$ & (R) Precentral Gyrus (BA 4) \\
\hline 6 & 336 & 0.014851548 & 4.504367 & $8,-4,-14$ & (R) Hypothalamus \\
\hline 7 & 80 & 0.010117263 & 3.6241639 & $-56,-18,33$ & (L) Postcentral Gyrus (BA 2) \\
\hline 8 & 80 & 0.010117263 & 3.6241639 & $-36,-34,45$ & (L) Inferior Parietal Lobule (BA 40) \\
\hline 9 & 64 & 0.008642835 & 3.1104991 & $27,-3,9$ & (R) Lentiform Nucleus (Putamen) \\
\hline 10 & 64 & 0.00938297 & 3.3538606 & $-38,4,12$ & (L) Insula (BA 13) \\
\hline \multicolumn{6}{|c|}{ Groups with decreased grey matter volumes } \\
\hline 1 & 208 & 0.00997 & 3.9280179 & $-56,-18,34$ & (L) Postcentral Gyrus (BA 2) \\
\hline 2 & 96 & 0.008955 & 3.6178029 & $6,44,0$ & (R) Anterior Cingulate (BA 32\&24) \\
\hline 3 & 96 & 0.009334 & 3.8218374 & $-40,-2,8$ & (L) Sub-lobar (Insula) \\
\hline 4 & 80 & 0.009279 & 3.7407575 & $0,33,-26$ & (L) Medial Frontal Gyrus (BA 11) \\
\hline 5 & 80 & 0.008896 & 3.611275 & $-40,4,12$ & (L) Sub-lobar (Insula) \\
\hline 6 & 80 & 0.009279 & 3.7407575 & $58,-13,16$ & (R) Postcentral Gyrus (BA 43) \\
\hline 7 & 56 & 0.009123 & 3.6994894 & $-14,40,10$ & (L) Anterior Cingulate (BA 32) \\
\hline 8 & 56 & 0.009123 & 3.6994894 & $-8,-52,26$ & (L) Posterior Cingulate (BA 31) \\
\hline
\end{tabular}




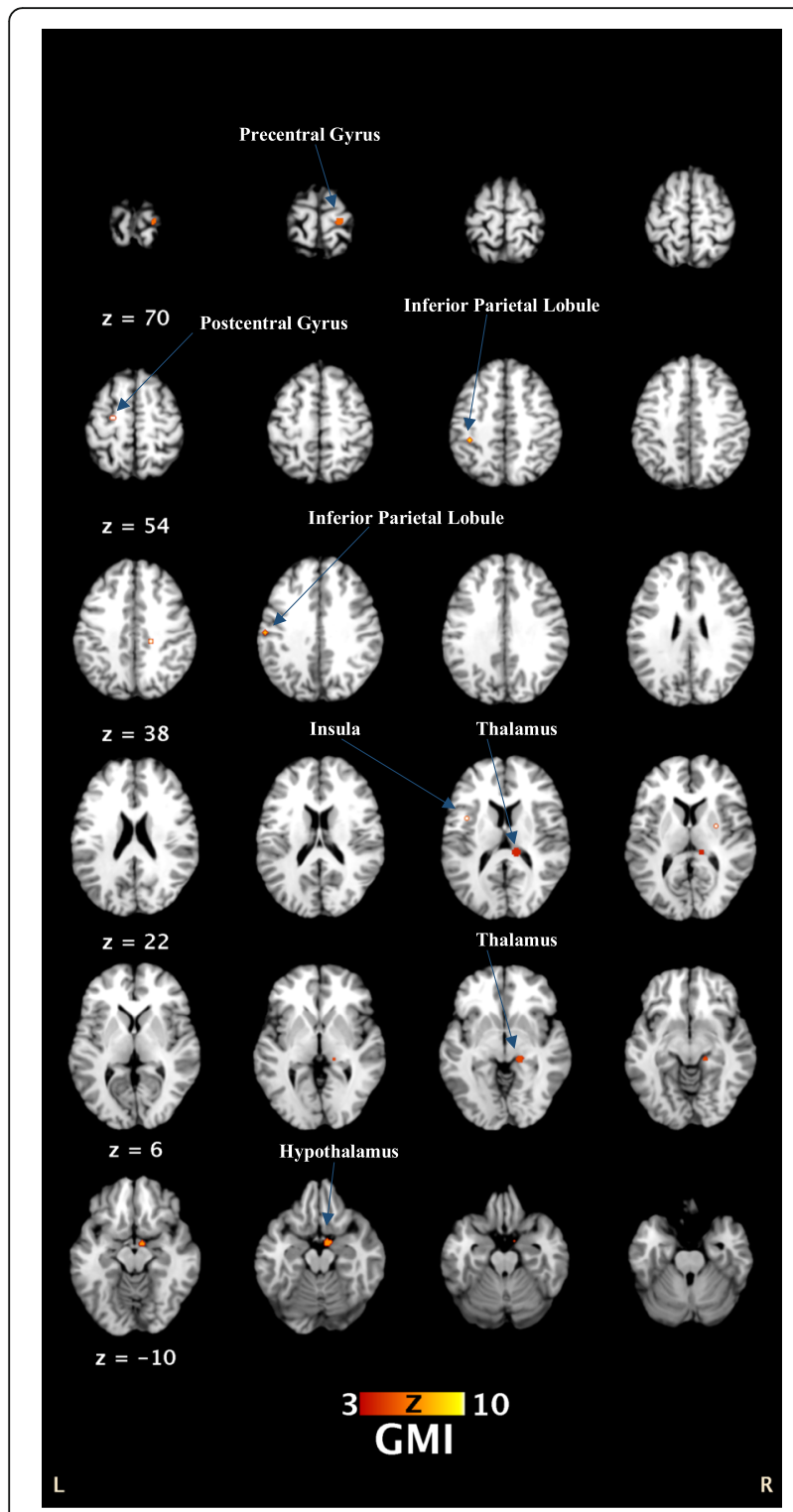

Fig. 2 Results from the ALE meta-analysis on grey matter increased volumes in patients with TS compared with healthy controls

to those of healthy controls. In contrast, grey matter volumes were significantly decreased in the bilateral postcentral gyrus, bilateral anterior cingulate, bilateral insula, left posterior cingulate and left postcentral gyrus of TS patients compared to those of healthy controls. For more details, see Table 2 and Fig. 2.

\section{Discussion}

To our knowledge, this is the first ALE analysis of VBMbased MRI studies in TS patients. The main findings of the present study were that grey matter volumes in the thalamus, precentral gyrus, postcentral gyrus, and lentiform nucleus were increased, whereas such volumes were decreased in the anterior cingulate and medial frontal gyrus of TS patients.

\section{Thalamus}

Several imaging studies have found increased total thalamic volumes in children and adults with TS [21]. In the present study, we found that grey matter volume was increased in the thalamus of TS patients, especially within the pulvinar nucleus. The pulvinar nucleus is the largest thalamic nucleus and has robust connectivity with the visual cortex [22]. Previous studies have shown that the most prominent differences in grey matter volumes between TS patients and healthy controls were in the pulvinar nucleus and several other motor nuclei [13]. There is a bidirectional connection between the pulvinar nucleus and the cortex [22]. The medial nucleus pulposus is extensively connected with the cortex, including the prefrontal cortex, orbital cortex and cingulate cortex [23]. Some regions that connect with the pulvinar nucleus are also associated with TS, such as prefrontal, orbital, and cingulate cortices.

Alternatively, altered thalamic regions (especially the pulvinar nucleus) in TS patients may be due to hyperactive motor circuitry and compensatory mechanisms derived from years of attempting to control tics. In consideration of widespread thalamic afferents and efferent, increased thalamic grey matter volumes in TS patients may be associated with multisensory integration in the thalamus and/or convergence of sensory inputs to cognitive-, motivational-, and /or movement-related cortical areas [13]. It is noteworthy that CSTC circuit dysfunction is thought to cause the occurrence of tics [24]. The pulvinar nucleus is a prototypic association nucleus that takes part in reciprocal cortico-cortical interactions and accelerates synchronized oscillatory activities in functionally related areas of the cortex [22].

\section{Putamen}

Findings from studies on the volume of the putamen in children with TS are inconsistent and have mostly focused on grey matter. For example, some studies have found smaller putamen in children and adults with TS $[25,26]$, while other studies have shown increased putamen volumes in such patients [13, 27, 28]. In our present meta-analysis, we found that the grey matter volume of the putamen was increased in TS patients. Interestingly, the dorsolateral putamina play a crucial role in motion planning by projecting the sensorimotor region [29-31]. The possible explanation for our finding is that the volume expansion of the dorsolateral putamina in TS patients might be caused by increased motor activity. 


\section{Other regions associated with TS}

In addition, we also found a decreased grey matter volume in the postcentral gyrus (motor-sensory gyrus), which indicates that primary motor pathways may be associated with TS [5]. It has been suggested that sensorymotor pathways may take part in the modulation of tics [32]. In contrast, grey matter volumes in insula have yielded mixed results. Some studies have found smaller insular cortices in children and adults with TS [24], whereas other studies have reported increased grey matter volumes in insular cortices of TS patients [5]. Regardless, these findings suggest that the insular cortex may play an important role in premonitory urges (PUs) $[33,34]$, which are based on interoceptive awareness [35]. Future studies are needed to further elucidate the role of the insular cortex in PUs.

Additionally, our present meta-analysis revealed decreased grey matter volumes in the medial frontal gyrus, which is consistent with several previous TS studies. Numerous studies have reported reductions in grey matter volumes in prefrontal cortices in TS patients, especially in the orbitofrontal cortex (OFC) [5, 13, 36]. For example, there is a negative correlation between OFC grey matter volume and tic severity [37]. Additionally, decreased grey matter volumes in the OFC have been reported in children with TS [13]. It was reported that cortical thickness of the right OFC decreased with age compared to the control group [38]. Besides, studies of adult TS patients showed a decrease in OFC grey matter volume, OFC cortical thinning [36, 39]. Changes in OFC activity may involve sensory aspects of twitching. These "uncomfortable feelings or bodily sensations" are referred to as PUs, which have a strong correlation with tic symptoms [40]. Task-specific fMRI studies should be performed in the future to explore the correlation between OFC activity and PUs in TS patients. Additionally, it seems that reduced OFC is found not only in children but also in adults with TS; although the volume of OFC found in this study was small, due to its important role in TS, future studies should follow up on this finding.

In our present meta-analysis, we found that grey matter volumes were reduced in the anterior cingulate gyrus (ACC) in TS patients. Previous studies showed cortical thinning and/or below-normal volumes in the subgenual ACC (sACC) [41]. The severity of the tic was also negatively correlated with tissue change in ACC on the right [37]. From functional imaging studies, tic production may be caused by changes in ACC [33, 42]. ACC activity increased with tic suppression, but ACC hypoperfusion was found in the quiescent period without tic suppression [42]. There was also a positive correlation between tic frequency and ACC activity $[41,43]$. ACC abnormalities, however, might appear to play a key role in TS pathology.
In summary, with the development of neuroimaging, MRI technology includes voxel-based morphometry (VBM) technology, diffusion tensor imaging (DTI), resting-state fMRI to make the research on neurological dysfunction of TS is further in-depth. Although the research conclusions are not completely consistent, this may be due to different research groups, but MRI studies support the existence of structural and dysfunctional CSTC loops in TS patients, which provide a basis for further research in the future [44]. Overall, the brain regions with grey matter abnormalities in TS patients that we reported in our present meta-analysis were mainly located in the CSTC circle. Future studies employing other methodologies (e.g., functional imaging and neural networks) will be needed to determine the role of the CSTC circuit in TS.

\section{Limitations}

Three limitations of our study should be acknowledged. First, the results reported in our meta-analysis comprised only six studies; future studies are needed with larger sample sizes. Second, several other factors (e.g., medications and comorbidities) should be considered in future MRI studies; we acknowledge that these factors may have accounted for the structural changes that we found in TS patients. Third, we only used the FDR to correct for our $p$ values, while we did not use the familywise error (FEW).

\section{Conclusion}

In the present study, we primarily found that TS patients exhibited grey matter increases in the thalamus and lentiform nucleus, and grey matter decreases in the anterior cingulate gyrus. Most regions identified were associated with CSTC circuitry. Further studies with large sample sizes are needed to confirm these changes in grey matter volumes in TS patients.

\section{Abbreviations}

TS: Tourette syndrome; ALE: Activation Likelihood Estimation; MRI: Magnetic Resonance Imaging; CSTC: Cortico-Striato-Thalamo-Cortical; VBM: Voxel-Based Morphometry; MNI: Montreal Neurological Institute; YGTSS: Yale Global Tic Severity Scale; OFC: OrbitoFrontal Cortex; ACC: Anterior Cingulate gyrus; FDRs: False Discovery Rates; FEW: Family-Wise Error; PUs: Premonitory Urges; HC: Health Control; GMV: Grey Matter Volume; WMV: White Matter Volume; GMT: Grey Matter Thickness; PSP: Premonitory Sensory Phenomena;

DOI: Duration Of IIIness; BA: Brodmann area; L: left; R: right

\section{Supplementary Information}

The online version contains supplementary material available at https://doi. org/10.1186/s12888-021-03187-1.

Additional file 1.

Acknowledgements

Thanks very much to all participants involved in this study. 


\section{Authors' contributions}

For this manuscript, YC gave suggestions for writing, analysis and revised the manuscript. YL joined the design of the work, gave suggestions for using the statistical analyses tool, and revised the manuscript. FW1 did substantial contributions to the conception and design of the work; and the acquisition, analysis, or interpretation of data for the work and drafted the manuscript. JY finalized the whole search work and gave suggestions for the manuscript. JL and LY contributed to statistical analyses and gave suggestions for the manuscript. FW2 polished the entire English writing. The author(s) read and approved the final manuscript.

\section{Funding}

This study is supported by the Special Fund of the Pediatric Medical Coordinated Development Center of Beijing Hospitals Authority, No. XTYB201802. Yonghua Cui was the Founder. The funding body had no further role in the study design, the collection, analysis, and interpretation of data, the writing of the manuscript and the decision to submit the paper for publication.

\section{Availability of data and materials}

The datasets used and/or analyzed during the current study are available from the corresponding author on reasonable request.

\section{Declarations}

\section{Ethics approval and consent to participate}

Not applicable.

\section{Consent for publication}

Not applicable.

\section{Competing interests}

All of the authors declare that they have no competing interests.

\section{Received: 5 April 2020 Accepted: 29 March 2021}

\section{Published online: 07 April 2021}

\section{References}

1. American Psychiatric Association, editor. Diagnostic and Statistical Manual of Mental Disorders. 5th ed. Arlington, VA: American Psychiatric Association; 2013.

2. Wen HLY, Rekik I, Wang S, Chen Z, Zhang J, Zhang Y, et al. Combining disrupted and discriminative topological properties of functional connectivity networks as neuroimaging biomarkers for accurate diagnosis of early Tourette syndrome children. Mol Neurobiol. 2018;55(54):3251-69. https://doi.org/10.1007/s12035-017-0519-1.

3. Mink: Neurobiology of basal ganglia and Tourette syndrome: basal ganglia circuits and thalamocortical outputs. Adv Neurol 2006, 99:89-98.

4. Martino DLJ. Tourette syndrome: Oxford University press: Oxford; 2013.

5. Liu YM, Wang W, Gao JQ, Yin PY, Zhang GH, Lv LP, et al. Structural abnormalities in early Tourette syndrome children: a combined voxel-based Morphometry and tract-based spatial statistics study. PLoS One. 2013;8(9): e76105. https://doi.org/10.1371/journal.pone.0076105.

6. Plessen KJW-LT, Hugdahl K, Feineigle P, Klein J. Altered interhemispheric connectivity in individuals with Tourette's disorder. Am J Psychiatry. 2004; 161(11):2028-37. https://doi.org/10.1176/appi.ajp.161.11.2028.

7. Sowell ERKE, Yoshii J, Thompson PM. Bansal R thinning of sensorimotor cortices in children with Tourette syndrome. Nat Neurosci. 2008;11(6):637-9. https://doi.org/10.1038/nn.2121.

8. Ramkiran SHL, Gaebler A, Shah NJ, Neuner I. Alterations in basal gangliaCerebello-Thalamo-cortical connectivity and whole brain functional network topology in Tourette's syndrome. Neurolmage Clinical. 2019;24:101998. https://doi.org/10.1016/j.nicl.2019.101998.

9. Yu Hamamoto YK. Tourette Syndrome. Brain Nerve. 2018;70(1 1):1237-45.

10. Peterson K, Scahill Z. Bronen basal ganglia volumes in patients with Gilles de la Tourette syndrome. Arch Gen Psychiatry. 2003;60(4):415-24. https:// doi.org/10.1001/archpsyc.60.4.415.

11. Peterson $S$, Scahill $Z$, Anderson $L$, et al. Regional brain and ventricular volumes in Tourette syndrome. Arch Gen Psychiatry. 2001;58(5):427-40. https://doi.org/10.1001/archpsyc.58.5.427.
12. Kassubek JJF, Ludolph AG. Heterogeneity of voxel-based morphometry findings in Tourette's syndrome: an effect of age? Ann Neurol. 2006;59(5): 872-3. https://doi.org/10.1002/ana.20848.

13. Greene DJ, Williams lii AC, Koller JM, Schlaggar BL, Black KJ. The Tourette Association of America neuroimaging C: brain structure in pediatric Tourette syndrome. Mol Psychiatry. 2017;22(7):972-80. https://doi.org/10.103 8/mp.2016.194.

14. Eickhoff SB, Bzdok D, Laird AR, Kurth F, Fox PT. Activation likelihood estimation meta-analysis revisited. Neuroimage. 2012;59(3):2349-61. https:// doi.org/10.1016/j.neuroimage.2011.09.017.

15. Turkeltaub PE, Eickhoff SB, Laird AR, Fox M, Wiener M, Fox P. Minimizing within-experiment and within-group effects in activation likelihood estimation meta-analyses. Hum Brain Mapp. 2012;33(1):1-13. https://doi. org/10.1002/hbm.21186.

16. Acar F, Seurinck R, Eickhoff SB, Moerkerke B. Assessing robustness against potential publication bias in activation likelihood estimation (ALE) metaanalyses for fMRI. PLoS One. 2018;13(11):e0208177. https://doi.org/10.1371/ journal.pone.0208177.

17. Turkeltaub PE, Eden GF, Jones KM, Zeffiro TA. Meta-analysis of the functional neuroanatomy of single-word reading: Method and validation. Neurolmage. 2002:16(3-part-PA):765-80.

18. Laird AR, Fox PM, Price CJ, Glahn DC, Uecker AM, Lancaster JL. ALE metaanalysis: controlling the false discovery rate and performing statistical contrasts. Hum Brain Mapp. 2005a;25(1):155-64. https://doi.org/10.1002/ hbm.20136.

19. Lancaster JL, Tordesillas-Gutierrez D, Martinez M, Salinas F, Evans A, Zilles K, et al. Bias between MNI and Talairach coordinates analyzed using the ICBM152 brain template. Human Brain Mapping. 2007;28(11):1194-205.

20. Brett. The MNI Brain and the Talairach Atlas. Cambridge: MA: MRC Cognition and Brain Sciences Unit; 1999.

21. Miller AMBR, Hao X, Sanchez-Pena JP, Sobel L, Liu J. Enlargement of thalamic nuclei in Tourette syndrome. Arch Gen Psychiatry. 2010;67(9):95564. https://doi.org/10.1001/archgenpsychiatry.2010.102.

22. Benarroch. Pulvinar: associative role in cortical function and clinical correlations. Neurology. 2015;84(7):738-47.

23. Shipp S. The functional logic of cortico-pulvinar connections. Philos Trans $\mathrm{R}$ Soc Lond Ser B Biol Sci. 2003;358(1438):1605-24. https://doi.org/10.1098/ rstb.2002.1213.

24. Amelia Draper GMJ, Morgan PS, Jackson SR. Premonitory urges are associated with decreased grey matter thickness within the insula and sensorimotor cortex in young people with Tourette syndrome. J Neuropsychol. 2016;10(1):143-53. https://doi.org/10.1111/jnp.12089.

25. Bloch MHLJ, Zhu H, Peterson BS. Caudate volumes in childhood predict symptom severity in adults with Tourette syndrome. Neurology. 2005;65(8): 1253-8. https://doi.org/10.1212/01.wnl.0000180957.98702.69.

26. Peterson BS, Thomas P, Kane MJ, Scahill L, Zhang H, Bronen R, et al. Basal ganglia volumes in patients with Gilles de la Tourette syndrome. Arch Gen Psychiatry. 2003;60(4):415-24. https://doi.org/10.1001/archpsyc.60.4.415.

27. Ludolph AGJF, Libal G, Ludolph AC, Fegert JM, Kassubek J. Greymatter abnormalities in boys with Tourette syndrome: magnetic resonance imaging study using optimised voxel-based morphometry. Br J Psychiatry. 2006;188(5):484-5. https://doi.org/10.1192/bjp.bp.105.008813.

28. Roessner VOS, Schmidt-Samoa C, Baudewig J, Dechent P, Rothenberger A et al. Increased putamen and callosal motor subregion in treatment-naïve boys with Tourette syndrome indicates changes in the bihemispheric motor network. Child Psychol Psychiatry. 2011;52(3):306-14. https://doi.org/1 0.1111/j.1469-7610.2010.02324.x.

29. Alexander GECM, DeLong MR. Basal ganglia-thalamocortical circuits: parallel substrates for motor, oculomotor, "prefrontal" and"limbic" functions. Prog Brain Res. 1990;85:119-49.

30. Draganski BKF, Kloppel S, Cook PA, Alexander DC, Parker GJ. Evidence for segregated and integrative connectivity patterns in the human basal ganglia. J Neurosci. 2008;28(28):7143-52. https://doi.org/10.1523/ JNEUROSCI.1486-08.2008.

31. Mary Mufford JC, Jahanshad N, van der Merwe C, Ding L, Groenewold N, Koen N, et al. Concordance of Genetic Variation That Increases Risk for Tourette Syndrome and That Influences Its Underlying Neurocircuitry. Transl Psychiatry. 2019;9(1):120.

32. Shprecher DKR. The Management of Tics. Mov Disord Clin Pract. 2009;24(1): 15-24. https://doi.org/10.1002/mds.22378. 
33. Bohlhalter S, Goldfine A, Matteson S, Garraux G, Hanakawa T, Kansaku K, et al. Neural correlates of tic generation in Tourette syndrome: an eventrelated functional MRI study. Brain. 2006;129(8):2029-37. https://doi.org/10.1 093/brain/awl050

34. Ganos C, Kassavetis P, Cerdan M, Erro R, Balint B, Price G, et al. Revisiting the syndrome of "obsessional slowness". Mov Disord Clin Pract. 2015;2(2):163-9. https://doi.org/10.1002/mdc3.12140.

35. Craig AD. How do you feel now? The anterior insula and human awareness. Nat Rev Neurosci. 2009;10(1):59-70. https://doi.org/10.1038/nrn2555.

36. Draganski B, Martino D, Cavanna AE, Hutton C, Orth M, Robertson MM, et al. Multispectral brain morphometry in Tourette syndrome persisting into adulthood. Brain. 2010;133(12):3661-75. https://doi.org/10.1093/brain/awq300

37. Muller-Vahl KR, Kaufmann J, Grosskreutz J, Dengler R, Emrich HM, Peschel T. Prefrontal and anterior cingulate cortex abnormalities in Tourette syndrome: evidence from voxel-based morphometry and magnetization transfer imaging. BMC Neurosci. 2009;10(1):47. https://doi.org/10.1186/1471-2202-10-47.

38. Fahim CYU, Das S, Lyttelton O, Chen J, Arnaoutelis R, et al.

Somatosensorymotor bodily representation cortical thinning in Tourette: effects of tic severity, age and gender. Cortex. 2010;46(6):750-60. https://doi. org/10.1016/j.cortex.2009.06.008.

39. Worbe YGE, Hartmann A, Valabrégue R, Chupin M, Tremblay L. Distinct structural changes underpin clinical phenotypes in patients with Gilles de la Tourette syndrome. Brain. 2010;133(12):3649-60. https://doi.org/10.1093/brain/awq293.

40. Li YWF, Liu J, Wen F, Yan C, Zhang J, Lu X, et al. The Correlation Between the Severity of Premonitory Urges and Tic Symptoms: A Meta-Analysis. J Child Adolesc Psychopharmacol. 2019;29(9):652-8.

41. O'Neill JPJ, Peterson BS. Cingulate role in Tourette syndrome. Handb Clin Neurol. 2019;166:165-221. https://doi.org/10.1016/B978-0-444-64196-0.00011-X.

42. Moriarty JCD, Schmitz B, Trimble MR, Ell PJ, Robertson MM. Brain perfusion abnormalities in Gilles de la Tourette's syndrome. Br J Psychiatry. 1995; 167(2):249-54. https://doi.org/10.1192/bjp.167.2.249.

43. Stern ESD, Chee KY, Holmes A, Robertson MM, Trimble M, et al. A functional neuroanatomy of tics in Tourette syndrome. Arch Gen Psychiatry. 2000; 57(8):741-8. https://doi.org/10.1001/archpsyc.57.8.741.

44. Naro A, Billeri L, Colucci VP, Le Cause M, De Domenico C, Ciatto L, et al, Brain functional connectivity in chronic tic disorders and Gilles de la Tourette syndrome. Prog Neurobiol. 2020;194:101884. https://doi.org/10.101 6/j.pneurobio.2020.101884.

\section{Publisher's Note}

Springer Nature remains neutral with regard to jurisdictional claims in published maps and institutional affiliations.

Ready to submit your research? Choose BMC and benefit from:

- fast, convenient online submission

- thorough peer review by experienced researchers in your field

- rapid publication on acceptance

- support for research data, including large and complex data types

- gold Open Access which fosters wider collaboration and increased citations

- maximum visibility for your research: over $100 \mathrm{M}$ website views per year

At $\mathrm{BMC}$, research is always in progress.

Learn more biomedcentral.com/submissions 